\title{
The Analysis of Self-Regulation Learning on Elementary Schools at the Rural Area in Indonesia
}

\author{
Rahmad Bala $^{1}$, Dwi Sulisworo ${ }^{2, *}$, Ika Maryani ${ }^{3}$ \\ ${ }^{1}$ Department of Islamic Education, Tarbiyah College of Kupang, Indonesia \\ ${ }^{2}$ Department of Physics Education, Ahmad Dahlan University, Indonesia \\ ${ }^{3}$ Department of Elementary Education, Ahmad Dahlan University, Indonesia
}

Received October 29, 2019; Revised December 24, 2019; Accepted December 30, 2019

Copyright $\bigcirc 2020$ by authors, all rights reserved. Authors agree that this article remains permanently open access under the terms of the Creative Commons Attribution License 4.0 International License

\begin{abstract}
Information that is easily accessed anytime and anywhere becomes one of the essential factors that influence educational practice at various levels. The ability of students since elementary school level in managing information during the learning process requires excellent self-regulation learning (SRL) skills. In the periphery that is relatively lacking in understanding the importance of this ability, it is necessary to see how the SRL profile of students is the basis for further policy development. This study aims to analyze the SRL profile of students in rural areas in Indonesia at the elementary school level. The research method used was survey research at three elementary schools in Kupang City, East Nusa Tenggara, and Indonesia. This city is one of the cities in a disadvantaged area group. The number of samples was 106 upper-class students from three elementary schools. The instrument used was a questionnaire with a scale of 1 to 5 (from not like me to like me). The analysis used is quantitative descriptive analysis and MANOVA for comparing schools. In the three schools studied, there was generally no difference in the students' SRL skills except for one school, which in the Plan aspect was relatively lower than other schools. This finding shows that elementary students in NTT relatively need to improve their SRL skills. In the measured aspects, which include Plan, Monitor, Control, and Reflect, all of the criteria are more than sufficient criteria but not yet up to proper criteria. The implication of this result is the need for policies from school managers to teach SRL at school. At the level of learning practices, it is necessary to apply many learning strategies that encourage the growth of SRL.
\end{abstract}

Keywords Self-Regulated Learning, Rural Areas, Primary Education, Elementary School

\section{Introduction}

Information that is easily accessed anytime and anywhere becomes one of the essential factors that influence educational practice at various levels. The ability of students since elementary school level in managing information during the learning process requires excellent self-regulation learning (SRL) skills. In Indonesia, the penetration of information technology has been quite high [1]. Almost all regions in Indonesia can access the internet. The IT literacy of elementary school children is also already high enough so that in their daily lives, they are used to using these tools. It is just that not all schools have developed policies for utilizing information from the internet in learning [2]. With this condition, it encourages the formation of behavior capable of self-regulation in managing information as part of the learning process becomes essential for students [3-6], including elementary students $[7,8]$. Self-regulated learning (SRL) refers to the deliberate and strategic adaptation of the learning process to change cognitive, motivational, and behavioral outcomes $[9,10]$. In the context of education and learning, self-regulation refers to proactively applying self-directive processes, cognitive behaviors, and emotions to attain goals, learn skills, and manage emotional reactions $[9,11$, 12]. The self-regulation process can be defined as making a plan, monitoring that plan, making changes to stay on track, and reflecting on what worked and what could be improved the next time [12]. The Self-Regulation Formative Questionnaire measures a student's perceived level of proficiency in the four essential components of self-regulation: Plan for and articulate what students want to accomplish; Immediately monitor progress and interference regarding student's goal; Control change by implementing specific strategies when things are not going as planned; and Reflect on what worked and what students can do better next time [9]. 
In urban schools, there is already an awareness of school management in utilizing information on the internet to support learning. However, on the contrary, in disadvantaged areas, many schools still run conventional learning processes. The ability to self-regulation in obtaining information from the internet is essential [13]. This condition is also related to the anticipation going forward; of course, schools in disadvantaged areas will also shift to use information from the internet for learning. In the periphery that is relatively lacking in understanding the importance of this ability, it is necessary to see how the SLR profile of students is the basis for further policy development. This study aims to analyze the SLR profile of students in rural areas in Indonesia at the elementary school level.

One of the success factors of learning is self-regulation. Self-regulation of learning is the ability to bring up and monitor one's thoughts, feelings, and behaviors to achieve learning goals. Self-regulation of learning is essential, so students have independence in learning using the information from the internet $[14,15]$. Self-regulation is the ability of a person to maintain or change his personality to be following moral values in society [16] using their competences [17]. The aspects of SRL are metacognition, motivation, and affirmative action. Stages of good self-regulation can achieve the expected learning goals $[18,19]$. SRL can also be in the form of cognitive regulation, motivation regulation, behavior regulation, and emotion regulation $[9,20,21]$. It is inseparable from the social support provided to them.

\section{Methods}

\subsection{Research Context}

Kupang is one of the disadvantaged areas in Indonesia. The SLR study in this area was conducted to obtain a picture that represented the SLR profile in other regions in Indonesia. There are 367 elementary schools in Kupang. In this study, three elementary schools were taken representing several different places in this city. The research method used was survey research at these schools. The samples are 105 upper-class students (4th, 5th, 6th grade). There are 51 students from MIS Al-Fitrah Oesapa Kupang City (SCH1), 25 students from MIS Fatul Mubin (SCH2), and 30 students from SD Muhammadiyah Kupang (SCH3). Data were collected in September and October 2019. Table 1 shows the sample structure of this study.

Table 1. Sample Structure

\begin{tabular}{|c|c|c|c|}
\hline \multirow{2}{*}{ Gender } & \multicolumn{3}{|c|}{ Schools } \\
\cline { 2 - 4 } & SCH1 & SCH2 & SCH3 \\
\hline Male & 31 & 13 & 13 \\
\hline Female & 20 & 12 & 17 \\
\hline Total & 51 & 25 & 30 \\
\hline
\end{tabular}

\subsection{Instrumentations}

The instrument used was a questionnaire with a scale of 1 to 5 (from not like me to like me). The overall self-regulation questionnaire was found to be highly reliable (22 items; $\alpha=.896)$. The plan subscale consisted of 5 items $(\alpha=.632)$, the monitor subscale consisted of 6 items $(\alpha=.704)$, the control subscale consisted of 6 items $(\alpha=.744)$, and the reflect subscale consisted of 5 items $(\alpha$ $=.682$ ). Table 2 shows the matrix for each factor and item.

Table 2. Questionnaire Matrix

\begin{tabular}{|c|c|c|c|c|}
\hline \multirow{2}{*}{ No } & \multirow{2}{*}{ Factors } & \multicolumn{2}{|c|}{ Item number } & \multirow{2}{*}{ Total } \\
\cline { 3 - 4 } & $\begin{array}{c}\text { Positive } \\
\text { Statements }\end{array}$ & $\begin{array}{c}\text { Negative } \\
\text { Statements }\end{array}$ & \\
\hline 1 & Plan & $1,2,3,4$ & 5 & 5 \\
\hline 2 & Monitor & $6,7,8,9,10$ & 11 & 6 \\
\hline 3 & Control & $12,13,14,15$ & 16,17 & 6 \\
\hline 4 & Reflect & $18,19,20,21$ & 22 & 5 \\
\hline
\end{tabular}

\subsection{Analysis Technique}

The analysis used is quantitative descriptive analysis. Descriptive data (average and standard deviation) was used for each factor in comparing profiles between schools. MANOVA on each SLR factor is used to see the effect of school places. The results of this MANOVA will be the basis for a comprehensive analysis of the Kupang area. Descriptive data together for three schools will also be the basis of analysis.

\section{Result}

\subsection{SRL Profile in Kupang}

Table 3 shows the score summary of three schools for each aspect of SRL. 
Table 3. Descriptive Statistics

\begin{tabular}{|c|c|c|c|c|c|c|c|c|}
\hline & \multirow{2}{*}{$\mathrm{N}$} & \multirow{2}{*}{ Mean } & \multirow{2}{*}{$\begin{array}{l}\text { Std. } \\
\text { Dev. }\end{array}$} & \multirow{2}{*}{ Var. } & \multicolumn{2}{|c|}{ Skew. } & \multicolumn{2}{|c|}{ Kurt. } \\
\hline & & & & & Stat. & Std. Error & Stat. & Std. Error \\
\hline Plan & 106 & 3.70 & .64 & .406 & -.656 & .235 & .463 & .465 \\
\hline Monitor & 106 & 3.39 & .66 & .430 & -.365 & .235 & -.049 & .465 \\
\hline Control & 106 & 3.55 & .61 & .375 & -.183 & .235 & .298 & .465 \\
\hline Reflect & 106 & 3.68 & .74 & .551 & -.488 & .235 & -.434 & .465 \\
\hline Valid N (listwise) & 106 & & & & & & & \\
\hline
\end{tabular}

From Table 3, the obtained score of all aspects have an average of less than 4.0 and also have negative skewness. Negative skewness means that the mode is higher than the mean. This data shows that many students who have SRL above average. This result implies to be studied further, especially for Plan and Reflect factors. Both factors have relatively large skewness values (-.656 for Plan factor; -.488 for Reflect factor), which means there is a large gap between students on SRL.

From the calculation of kurtosis, Plan and Control factors have positive kurtosis, while Monitor and Reflect have negative kurtosis. The Reflect factor has a significant negative kurtosis value (-434). This value indicates that students tend to spread their abilities in this factor. It needs to be studied more deeply in students, especially those who have low Reflection ability.

The lowest score is on the Monitor aspect (3.40), whereas in other aspects the relative equal around 3.60. Based on a maximum score of 5.0, as mentioned in the method section, the SRL of students is still low enough to support the desired learning in this era. Some strategies for increasing SRL are essential to improve the SRL of students. A detailed analysis of this result would be found in the Discussion section.

\subsection{SRL Comparison between Schools}

Table 4 shows descriptive statistics for each elementary school. From Table 3, the second column (Mean), SCH2 tends to have the lowest average score and the highest standard deviation of all aspects compared to other schools. This result will be the basis for paying attention to the situation at $\mathrm{SCH} 2$.

However, overall, in the three schools, the mean for SRL, no one reached more than 4.0 (High). There are many models for being able to improve SRL through various systematic exercises in learning. Self-regulation is an essential component of psychosocial theories about behavior - low of SRL associated with poor adherence to the objectives to be achieved. The implication of this result is the need for policies from school managers to improve the SRL At the level of learning practices, and it is necessary to apply collaborative learning models that encourage the growth of SRL.

Table 4. Descriptive Statistics for each school

\begin{tabular}{|c|c|c|c|c|}
\hline & Schools & Mean & $\begin{array}{l}\text { Std. } \\
\text { Dev. }\end{array}$ & $\mathrm{N}$ \\
\hline \multirow{4}{*}{ Plan } & $\mathrm{SCH} 1$ & 3.8157 & .50730 & 51 \\
\hline & $\mathrm{SCH} 2$ & 3.3440 & .85151 & 25 \\
\hline & $\mathrm{SCH} 3$ & 3.7933 & .53171 & 30 \\
\hline & Total & 3.6981 & 63680 & 106 \\
\hline \multirow{4}{*}{ Monitor } & $\mathrm{SCH} 1$ & 3.3431 & 66283 & 51 \\
\hline & $\mathrm{SCH} 2$ & 3.3200 & .71673 & 25 \\
\hline & $\mathrm{SCH} 3$ & 3.5444 & .58548 & 30 \\
\hline & Total & 3.3947 & .65600 & 106 \\
\hline \multirow{4}{*}{ Control } & SCH1 & 3.5392 & 61877 & 51 \\
\hline & $\mathrm{SCH} 2$ & 3.5667 & 64190 & 25 \\
\hline & $\mathrm{SCH} 3$ & 3.5611 & .59610 & 30 \\
\hline & Total & 3.5519 & 61221 & 106 \\
\hline \multirow{4}{*}{ Reflect } & SCH1 & 3.6784 & .73656 & 51 \\
\hline & $\mathrm{SCH} 2$ & 3.5120 & .84277 & 25 \\
\hline & $\mathrm{SCH} 3$ & 3.8133 & .65587 & 30 \\
\hline & Total & 3.6774 & .74249 & 106 \\
\hline
\end{tabular}

Table 5 shows the test of between-subject effects. From this table, there are significant differences between schools in the Plan aspect (Sig. $=0.005$ ) for p-value $=$ 0.05 . In other aspects it tends not to be significantly different $($ Sig. $=0.336$ for Monitors; Sig. $=0.979$ for Control and Sig. $=0.328$ for Reflect). 
Table 5. Tests of Between-Subjects Effects

\begin{tabular}{|c|c|c|c|c|c|c|}
\hline Source & Dependent Variable & Type III Sum of Squares & df & Mean Square & $\mathrm{F}$ & Sig. \\
\hline \multirow{4}{*}{ Corrected Model } & Plan & 4.112 & 2 & 2.056 & 5.505 & .005 \\
\hline & Monitor & .948 & 2 & .474 & 1.103 & .336 \\
\hline & Control & .016 & 2 & .008 & .021 & .979 \\
\hline & Reflect & 1.238 & 2 & .619 & 1.126 & .328 \\
\hline \multirow{4}{*}{ Intercept } & Plan & 1290.802 & 1 & 1290.802 & 3456.212 & .000 \\
\hline & Monitor & 1121.082 & 1 & 1121.082 & 2610.295 & .000 \\
\hline & Control & 1224.266 & 1 & 1224.266 & 3205.594 & .000 \\
\hline & Reflect & 1302.790 & 1 & 1302.790 & 2368.820 & .000 \\
\hline \multirow{4}{*}{ Schools } & Plan & 4.112 & 2 & 2.056 & 5.505 & .005 \\
\hline & Monitor & .948 & 2 & .474 & 1.103 & .336 \\
\hline & Control & .016 & 2 & .008 & .021 & .979 \\
\hline & Reflect & 1.238 & 2 & .619 & 1.126 & .328 \\
\hline \multirow{4}{*}{ Error } & Plan & 38.468 & 103 & .373 & & \\
\hline & Monitor & 44.237 & 103 & .429 & & \\
\hline & Control & 39.337 & 103 & .382 & & \\
\hline & Reflect & 56.647 & 103 & .550 & & \\
\hline \multirow{4}{*}{ Total } & Plan & 1492.240 & 106 & & & \\
\hline & Monitor & 1266.694 & 106 & & & \\
\hline & Control & 1376.639 & 106 & & & \\
\hline & Reflect & 1491.320 & 106 & & & \\
\hline \multirow{4}{*}{ Corrected Total } & Plan & 42.580 & 105 & & & \\
\hline & Monitor & 45.185 & 105 & & & \\
\hline & Control & 39.354 & 105 & & & \\
\hline & Reflect & 57.886 & 105 & & & \\
\hline
\end{tabular}

The results from Table 4 imply that inter-schools have the same SRL score on each factor. This result also means that a generic strategy can be applied to all schools to improve the SRL. A Post Hoc analysis with Bonferroni was conducted to find out the differences between schools in more detail. The results are shown in Table 6 . 
Table 6. Multiple Comparisons Bonferroni

\begin{tabular}{|c|c|c|c|c|c|}
\hline Dependent Variable & (I) Schools & (J) Schools & Mean Difference (I-J) & Std. Error & Sig. \\
\hline \multirow{6}{*}{ lan } & \multirow{2}{*}{$\mathrm{SCH} 1$} & $\mathrm{SCH} 2$ & $.4717^{*}$ & .14920 & .006 \\
\hline & & $\mathrm{SCH} 3$ & .0224 & .14061 & 1.000 \\
\hline & \multirow{2}{*}{$\mathrm{SCH} 2$} & SCH1 & $-.4717^{*}$ & .14920 & .006 \\
\hline & & $\mathrm{SCH} 3$ & $-.4493^{*}$ & .16549 & .023 \\
\hline & \multirow{2}{*}{$\mathrm{SCH} 3$} & $\mathrm{SCH} 1$ & -.0224 & .14061 & 1.000 \\
\hline & & $\mathrm{SCH} 2$ & $.4493^{*}$ & .16549 & .023 \\
\hline \multirow{6}{*}{ Monitor } & \multirow{2}{*}{$\mathrm{SCH} 1$} & $\mathrm{SCH} 2$ & .0231 & .16000 & 1.000 \\
\hline & & $\mathrm{SCH} 3$ & -.2013 & .15079 & .554 \\
\hline & \multirow{2}{*}{$\mathrm{SCH} 2$} & SCH1 & -.0231 & .16000 & 1.000 \\
\hline & & $\mathrm{SCH} 3$ & -.2244 & .17747 & .627 \\
\hline & \multirow{2}{*}{$\mathrm{SCH} 3$} & SCH1 & .2013 & .15079 & .554 \\
\hline & & $\mathrm{SCH} 2$ & .2244 & .17747 & .627 \\
\hline \multirow{6}{*}{ Control } & \multirow{2}{*}{$\mathrm{SCH} 1$} & $\mathrm{SCH} 2$ & -.0275 & .15088 & 1.000 \\
\hline & & $\mathrm{SCH} 3$ & -.0219 & .14219 & 1.000 \\
\hline & \multirow{2}{*}{$\mathrm{SCH} 2$} & $\mathrm{SCH} 1$ & .0275 & .15088 & 1.000 \\
\hline & & $\mathrm{SCH} 3$ & .0056 & .16735 & 1.000 \\
\hline & \multirow{2}{*}{$\mathrm{SCH} 3$} & SCH1 & .0219 & .14219 & 1.000 \\
\hline & & $\mathrm{SCH} 2$ & -.0056 & .16735 & 1.000 \\
\hline \multirow{6}{*}{ Reflect } & \multirow{2}{*}{$\mathrm{SCH} 1$} & $\mathrm{SCH} 2$ & .1664 & .18106 & 1.000 \\
\hline & & $\mathrm{SCH} 3$ & -.1349 & .17063 & 1.000 \\
\hline & \multirow{2}{*}{$\mathrm{SCH} 2$} & SCH1 & -.1664 & .18106 & 1.000 \\
\hline & & $\mathrm{SCH} 3$ & -.3013 & .20083 & .410 \\
\hline & \multirow{2}{*}{$\mathrm{SCH} 3$} & $\mathrm{SCH} 1$ & .1349 & .17063 & 1.000 \\
\hline & & $\mathrm{SCH} 2$ & .3013 & .20083 & .410 \\
\hline
\end{tabular}

Table 6 shows the differences for each school in each aspect. For the Plan aspects, $\mathrm{SCH} 1$ and $\mathrm{SCH} 2$ differ significantly (0.006) but do not differ significantly from $\mathrm{SCH} 3$ (1.000). $\mathrm{SCH} 2$ is significantly different from $\mathrm{SCH} 3$ (0.023). For Monitor aspects, $\mathrm{SCH} 1$ and $\mathrm{SCH} 2$ did not differ significantly (1.000) and also did not differ significantly from $\mathrm{SCH} 3 \quad(0.554)$. $\mathrm{SCH} 2$ is not significantly different from $\mathrm{SCH} 3$ (0.726). For the Control aspect, $\mathrm{SCH} 1$ and $\mathrm{SCH} 2$ did not differ significantly (1.000) and also did not differ significantly from SCH3 (1.000). $\mathrm{SCH} 2$ is not significantly different from $\mathrm{SCH} 3$ (1.000). For the Reflect aspect, SCH1 and SCH2 did not differ significantly (1.000) and also did not differ significantly from SCH3 (1.000). SCH2 does not differ significantly from $\mathrm{SCH} 3$ (0.410). From these results, there is a tendency that attention needs to be addressed to $\mathrm{SCH} 2$, especially on the Plan aspect. In other aspects, there is no significant difference, although the score still needs to be improved for all schools.

\section{Discussions}

SRL refers to the ability to understand and control the learning environment. The ability of SRL includes setting goals (Plan), self-monitoring (Monitor), self-instruction (Control), and self-reinforcement (Reflect) $[9,11,12]$. SRL is different and does not constitute mental ability or skills in academic performance. SRL is a process of self-direction through a series of behaviors to turn mental abilities into skills and habits through a process of development that arises from guided practice and feedback. With a good SRL, students will be better able to deal with the development of their learning environment, including using information from the internet world. This full and heavy information needs to be in lined with good 
SRL. From the results of the study, it appears that elementary schools in NTT still need to be improved in all aspects, because there was no score of SRL factors that reached 4.0. Various efforts need to be made to improve this.

Due to the importance of SRL, teachers and school policymakers in NTT need to teach SRL explicitly in elementary schools. This suggestion also refers to the other result of research conducted by [5] and [22]. It is essential to determine the strategies that encourage students to apply when dealing with information in cyberspace. Activities that can be carried out to encourage better SRL include providing an explanation of the benefits and importance of SRL, explicitly teaching SRL strategies, and helping to identify when and how to use SRL when dealing with information for their learning $[4,11]$. With this activity, it can be expected that there will be an increase in SRL in elementary schools in NTT. Re-role of school policymakers is essential in this endeavor. The era of digital technology faced in the daily activities of students cannot be ignored without giving or teaching skills to manage information for student growth and development. However, SRL is closely related to how to regulate emotions, cognition, behavior, and environmental aspects.

This result in the knowledge aspect implies that SRL in students in the three schools studied still needs to be improved with a variety of relevant strategies. By assuming that these results can be generalized, elementary students in NTT need to be given attention to improving SRL in the face of current communication and information technology. The wise use of technology and the proper use of information that supports their learning need to be promoted. Based on implications at the level of practical learning, teachers need to develop strategies both explicitly and implicitly to teach SRL to students. Also, the policy implication is that managers of education and schools need to make regulations to ensure that the process of improving the SRL of these students can be measured. To further utilize the results of this research, a study to develop strategies to teach SRL and its application needs to be applied to ensure improvements in SRL skills in elementary students in NTT.

\section{Conclusions}

Form the study in the three schools, and there was generally no difference in the students' SRL skills except for one school, which in the Plan aspect was relatively lower than other schools. This finding shows that elementary students in NTT relatively need to improve their SRL skills. In the measured aspects, which include Plan, Monitor, Control, and Reflect, all of the criteria are more than sufficient but not yet up to proper criteria. These results need to be improved to achieve functional skills by developing various policies both implicitly and explicitly by education policymakers in NTT, policymakers in schools, and teachers in the learning process in the classroom.

\section{Acknowledgements}

Research and Community Services Institute of Ahmad Dahlan University have funded this research. Tarbiyah College of Kupang has facilitated the data collection process.

\section{REFERENCES}

[1] D. Sulisworo. The paradox on IT literacy and science's learning achievement in secondary school. International Journal of Evaluation and Research in Education, Vol. 2, No. 4, 149-152, 2013.

[2] D. Sulisworo. The Contribution of the Education System Quality to Improve the Nation's Competitiveness of Indonesia. Journal of Education and Learning, Vol. 10, No. 2, 127-138, 2016.

[3] Y. L. Chiu, J. C. Liang, C. C. Tsai. Internet-specific epistemic beliefs and self-regulated learning in online academic information searching. Metacognition and learning, Vol. 8, No. 3, 235-260, 2013.

[4] T. Mooij. Education and ICT-based self-regulation in learning: Theory, design and implementation. Education and Information Technologies, Vol. 14, No. 1, 3, 2009.

[5] C. Zheng, J. C. Liang, Y. F. Yang, C. C. Tsai. The relationship between Chinese university students' conceptions of language learning and their online self-regulation. System, 57, 66-78, 2016.

[6] K. E. Dunn, G. C. Rakes. Exploring online graduate students' responses to online self-regulation training. Journal of Interactive Online Learning, Vol. 13, No. 4, 2015.

[7] J. J. Montroy, R. P. Bowles, L. E. Skibbe, M. M. McClelland, F. J. Morrison. The development of self-regulation across early childhood. Developmental Psychology, Vol. 52, No. 11, 1744, 2016.

[8] P. Wisniewski, A. K. Ghosh, H. Xu, M. B. Rosson, J. M. Carroll. Parental Control vs. Teen Self-Regulation: Is there a middle ground for mobile online safety? In Proceedings of the 2017 ACM Conference on Computer Supported Cooperative Work and Social Computing (pp. 51-69). ACM, 2017.

[9] E. Panadero. A review of self-regulated learning: Six models and four directions for research. Frontiers in psychology, Vol. 8, 422, 1-28, 2017.

[10] I. Nakonechnyi, Y. Galan. Development of behavioral self-regulation of adolescents in the process of mastering martial arts. Journal of Physical Education and Sport, Vol. 17, 1002-1008, 2017. 
[11] D. Persico, K. Steffens. Self-regulated learning in technology enhanced learning environments. In Technology Enhanced Learning (pp. 115-126). Springer, Cham, 2017.

[12] B. J. Zimmerman, D. H. Schunk. Self-regulated learning and performance: An introduction and an overview. In Handbook of self-regulation of learning and performance (pp. 15-26). Routledge, 2011.

[13] F. Inan, E. Yukselturk, M. Kurucay, R. Flores. The impact of self-regulation strategies on student success and satisfaction in an online course. International Journal on E-learning, Vol. 16, No. 1, 23-32, 2017.

[14] W. G. Ganpat, J. Ramjattan, R. Strong. Developing an understanding of barriers to ICT use: Caribbean extension officer's ICT use, acceptance, and self-efficacy, 2016.

[15] B. J. G. Espinosa, G. C. T. Sepúlveda, M. S. R. Montoya. Self-motivation challenges for student involvement in the Open Educational Movement with MOOC. International Journal of Educational Technology in Higher Education, Vol. 12, No. 1, 91-103, 2015.

[16] Y. C. Kuo, A. E. Walker, K. E. Schroder, B. R. Belland. Interaction, Internet self-efficacy, and self-regulated learning as predictors of student satisfaction in online education courses. The internet and higher education, Vol. 20, 35-50, 2014.

[17] K. Aesaert, J. Voogt, E. Kuiper, J. van Braak. Accuracy and bias of ICT self-efficacy: An empirical study into students' over-and underestimation of their ICT competences. Computers in Human Behavior, Vol. 75, 92-102, 2017.

[18] M. de Fátima Goulão, R. C. Menedez. Learner autonomy and self-regulation in eLearning. Procedia-Social and Behavioral Sciences, 174, 1900-1907, 2015.

[19] Y. Zhu, W. Au, G. Yates. University students' self-control and self-regulated learning in a blended course. The Internet and higher education, Vol. 30, 54-62, 2016.

[20] U. Matzat, E. M. Vrieling. Self-regulated learning and social media - a 'natural alliance'? Evidence on students' self-regulation of learning, social media use, and student-teacher relationships. Learning, Media and Technology, Vol. 41, No. 1, 73-99, 2016.

[21] M. H. Cho, Y. Cho. Self-regulation in three types of online interaction: a scale development. Distance Education, Vol. 38, No. 1, 70-83, 2017.

[22] C. W. Tsai. How much can computers and internet help? A long-term study of Web-Mediated Problem-Based Learning and Self-Regulated Learning. In User Perception and Influencing Factors of Technology in Everyday Life (pp. 248-264). IGI Global, 2013. 